\title{
Optimal Policies for Deteriorating Items with Maximum Lifetime and Two-Level Trade Credits
}

\author{
Nita H. Shah, ${ }^{1}$ Dushyantkumar G. Patel, ${ }^{2}$ and Digeshkumar B. Shah ${ }^{3}$ \\ ${ }^{1}$ Department of Mathematics, Gujarat University, Ahmedabad, Gujarat 380009, India \\ ${ }^{2}$ Department of Mathematics, Government Polytechnic for Girls, Ahmedabad, Gujarat 380015, India \\ ${ }^{3}$ Department of Mathematics, L.D. College of Engineering, Ahmedabad, Gujarat 380015, India \\ Correspondence should be addressed to Nita H. Shah; nitahshah@gmail.com
}

Received 4 February 2014; Accepted 24 March 2014; Published 10 April 2014

Academic Editor: Onesimo Hernandez-Lerma

Copyright (C) 2014 Nita H. Shah et al. This is an open access article distributed under the Creative Commons Attribution License, which permits unrestricted use, distribution, and reproduction in any medium, provided the original work is properly cited.

\begin{abstract}
The retailer's optimal policies are developed when the product has fixed lifetime and also the units in inventory are subject to deterioration at a constant rate. This study will be mainly applicable to pharmaceuticals, drugs, beverages, and dairy products, and so forth. To boost the demand, offering a credit period is considered as the promotional tool. The retailer passes credit period to the buyers which is received from the supplier. The objective is to maximize the total profit per unit time of the retailer with respect to optimal retail price of an item and purchase quantity during the optimal cycle time. The concavity of the total profit per unit time is exhibited using inventory parametric values. The sensitivity analysis is carried out to advise the decision maker to keep an eye on critical inventory parameters.
\end{abstract}

\section{Introduction}

In business transactions, the offer of settling dues against the purchases without any interest charges from the supplier is attractive for the retailer. During this permissible delay period, the retailer can sell the item and generate the revenue and incur interest on it by depositing in the bank or financial firms. Goyal [1] developed a mathematical model to compute economic order quantity when delay in payments is permissible. The literature review by Shah et al. [2] gave upto-date references on trade credit and inventory modeling. Sarkar et al. [3] developed an inventory model considering trade credit and price discount offer.

Huang [4] established that the retailer is further beneficial if the credit period which is received from the supplier is passed onto the customers. The economic order quantity is computed when the supplier offers the retailer a credit period $M$ and the retailer passes a credit period $N$ to the customers with $N<M$. This scenario is known as two-level trade credits. Huang $[5,6]$ extended the above model with floor constraint and finite replenishment rate, respectively. Teng and Chang [7] analyzed the two-level trade credit scenario by relaxing the assumption $N<M$ Pal et al. [8] analyzed three-stage trade credit policy in a three-layer supply chain.

Another important parameter for inventory modeling is deterioration of items, namely, volatile and radioactive chemicals, medicines and drugs, fruits and vegetables, electronic gadgets, and so forth. Ghare and Schrader [9] gave first inventory model for exponentially decaying items. Shah et al. [10], Goyal and Giri [11], and Bakker et al. [12] collected articles on deteriorating inventory modeling. Leśniewski and Bartoszewicz [13] applied the control-theoretic approach to design a new replenishment strategy for inventory systems with perishable stock. Sana [14] discussed an article on optimal selling price and lot size with time varying deterioration and partial backlogging. Most of the articles cited in these reviews considered infinite lifetime of the product.

Actually, every product (including human being) has its maximum lifetime [3, 15-19].

In this paper, we analyze an EOQ model for the retailer under the following assumptions: (1) items in inventory are deteriorating continuously and have maximum lifetime and (2) the retailer follows two-level trade credit financing. The goal is to maximize total profit per unit time for retailer with 
respect to cycle time. Finally, we carry out sensitivity analysis to study the effects of an inventory parameter at a time on optimal solution. Based on it managerial insights are discussed for the retailer. The paper is organized as follows. The introduction is given in Section 1. In Section 2, notations and assumptions are listed to formulate the proposed problem. Section 3 is about derivation of profit function. In Section 4, numerical examples and sensitivity analysis are carried out to validate the mathematical model. The conclusion and the future scope of the developed model are exhibited in Section 5 .

\section{Notations and Assumptions}

We will use following notations and assumptions to develop the mathematical model of the problem under consideration.

\subsection{Notations}

a: constant demand rate,

$A$ : ordering cost per order,

$C$ : purchase cost per unit,

$s$ : unit sale price, where $s>C$,

$h$ : inventory holding cost (excluding interest charges) per unit per unit time,

$I_{e}:$ interest earned per $\$$ per year,

$I_{c}$ : interest charged per $\$$ for unsold stock per annum by the supplier,

$M$ : credit period offered by the supplier to the retailer,

$N$ : credit period offered by the retailer to the customer,

$\theta(t)$ : time varying deterioration rate at time $t$, where $0 \leq$ $\theta(t) \leq 1$

$m$ : maximum lifetime (in years) of the deteriorating item,

$I(t)$ : inventory level at any instant of time $t, 0 \leq t \leq T$,

$T$ : cycle time (a decision variable),

Q: procurement quantity per cycle (a decision variable), $\pi(T)$ : retailer's total profit per unit time.

\subsection{Assumptions}

(1) The inventory system under study deals with deteriorating items having expiry rate. The deterioration rate tends to 1 when time tends to maximum lifetime $m$. Following Sarkar [20], Chen and Teng [21], and Wang et al. [22], the functional form for deterioration rate is

$$
\theta(t)=\frac{1}{1+m-t} ; \quad 0 \leq t \leq T .
$$

There is no repair or replacement of deteriorated items during the cycle time.

(2) The planning horizon is infinite.

(3) Shortages are not allowed. Lead time is zero or negligible.
(4) The credit period $N$ offered to the customers by the retailer results in revenue inflow in $[N, T+N]$ [23].

(5) When $M \leq T+N$, the retailer would pay interest during $[M, T+N]$ at the rate $I_{c}$ for unsold stock. When $M>T+N$, the retailer will settle the account at $M$ and does not incur any interest charges during the cycle.

(6) The retailer generates revenue by selling items and earns interest during $[0, M]$. Thus, for $N \leq M$, the retailer accrues revenue and earns interest during $[N, M]$ with rate $I_{e}$.

\section{Mathematical Model}

The retailer's initial inventory of $Q$ units depletes to zero at $t=T$ due to combined effect of demand and time-dependent deterioration. Hence, the rate of change of inventory level at any instant of time $t$ is governed by the differential equation

$$
\frac{d I(t)}{d t}=-a-\theta(t) I(t), \quad 0 \leq t \leq T
$$

with $I(T)=0$. The solution of differential equation (2) is

$$
I(t)=a(1+m-t) \ln \left(\frac{1+m-t}{1+m-T}\right) .
$$

Consequently, the retailer's order quantity is

$$
Q=I(0)=a(1+m) \ln \left(\frac{1+m}{1+m-T}\right) .
$$

The sales revenue is

$$
\mathrm{SR}=s \int_{0}^{T} a d t=s a T
$$

The ordering cost is $\mathrm{OC}=A$.

The purchase cost of $Q$ unit is $P C=C Q$.

The holding cost is

$$
\begin{aligned}
\mathrm{HC}=h \int_{0}^{T} I(t) d t \\
=a h\left[\frac{1}{2} \ln \left(\frac{1+m}{1+m-T}\right)\left(m^{2}+1\right)+\ln \left(\frac{1+m}{1+m-T}\right) m\right. \\
\left.\quad-\frac{1}{2} T-\frac{1}{2} m T+\frac{1}{4} T^{2}\right] .
\end{aligned}
$$

Next, we need to compute interest earned and interest charges for the retailer in the following two cases.

(A) Suppose $M \geq N$.

Case $1(M \geq T+N)$. Here, the retailer has sold all the items before the permissible time $M$, so the interest charged is zero; that is, $\mathrm{IC}_{1}=0$. The retailer spawns revenue from the beginning of the cycle and settles the account at time N. So the retailer's interest earned per cycle is

$$
\mathrm{IE}_{1}=s I_{e}\left[\int_{N}^{T+N} \int_{N}^{t+N} a d v d t+(M-T-N) \int_{0}^{T} a d t\right] .
$$


Case $2(M \leq T+N)$. Here, the retailer lacks the fund to settle the account at $M$ because the customer will settle the account at time $T+N$. So, the retailer will pay interest charges as

$$
\mathrm{IC}_{2}=C I_{c} \int_{M}^{T+N} I(t-N) d t
$$

and interest earned on the generated revenue at the rate $I_{e}$ during $[N, M]$, which is given by

$$
\mathrm{IE}_{2}=s I_{e} a\left[\frac{1}{2} T^{2}+M-N\right] .
$$

Hence, the total profit per unit time for retailer is

$$
\pi(T)= \begin{cases}\pi_{1}(T), & 0 \leq T \leq M-N \\ \pi_{2}(T), & T \geq M-N\end{cases}
$$

where

$$
\begin{aligned}
& \pi_{1}(T)=\frac{1}{T}\left\{\mathrm{SR}-\mathrm{PC}-\mathrm{OC}-\mathrm{HC}-\mathrm{IC}_{1}+\mathrm{IE}_{1}\right\}, \\
& \pi_{2}(T)=\frac{1}{T}\left\{\mathrm{SR}-\mathrm{PC}-\mathrm{OC}-\mathrm{HC}-\mathrm{IC}_{2}+\mathrm{IE}_{2}\right\} .
\end{aligned}
$$

(B) Suppose $M \leq N$. Here, the retailer does not generate any revenue from the customer. So the interest earned by the retailer $\mathrm{IE}_{3}=0$. The interest is charged for all the items and is given by

$$
\mathrm{IC}_{3}=\mathrm{CI}_{c}\left[(N-M) Q+\int_{N}^{T+N} I(t-N) d t\right] .
$$

The total profit per unit time for retailer is

$$
\pi_{3}(T)=\frac{1}{T}\left\{\mathrm{SR}-\mathrm{PC}-\mathrm{OC}-\mathrm{HC}-\mathrm{IC}_{3}+\mathrm{IE}_{3}\right\} .
$$

The goal is to maximize the total profit per unit time with respect to cycle time when items in inventory are deteriorating and having maximum lifetime. The nonlinearity of the objective functions in (11)-(12), (14) does not allow us to obtain the closed form solution. We analyze the model with numerical values for the inventory parameters in the next section.

\section{Numerical Examples}

The necessary condition to optimize profit function is to set $\partial \pi_{i}(T) / \partial T=0$ and follow the steps given below to select the best solution for the retailer.

Step 1. Assign values to all inventory parameters.

Step 2. For $M \geq N$, solve $\partial \pi_{1} / \partial T=0$ and $\partial \pi_{2} / \partial T=0$.

If $M \geq T+N$, then compute total profit per unit time from (11) otherwise compute $\pi_{2}$ from (12). By knowing optimum cycle time $T$, retailer can determine order quantity using (4).

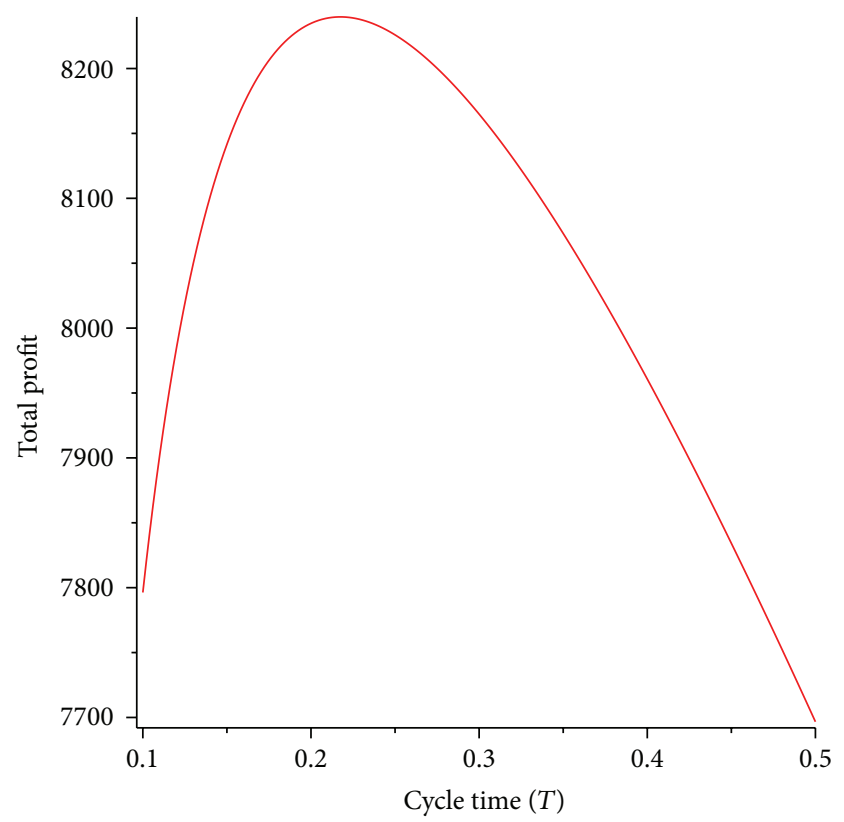

FIGURE 1: Concavity of total profit with respect to cycle time $T$ for $M \geq T+N$

Step 3. For $M<N$, the retailer's replenishment time can be calculated by setting $\partial \pi_{3} / \partial T=0$. Obtain the total profit per unit time $\pi_{3}$ from (14) and order quantity from (4).

We consider the following examples to validate the mathematical formulation.

Example 1. Consider $A=\$ 150$ per order, $C=\$ 6$ per unit, $a=1000$ units, $s=\$ 15$ per unit, $I_{e}=10 \% / \$ /$ year, $I_{c}=$ $15 \% / \$ /$ year, $M=0.8$ year, $N=0.4$ year, and $m=2$ years. Then optimum cycle time is 0.2175 years and corresponding profit is $\$ 8239.78$. Clearly, here $M \geq T+N$ is seen. The retailer's purchase is 226 units. The concavity of the profit function is exhibited in Figure 1.

Example 2. Take $N=0.72$ years and all other inventory parameters are as given in Example 1. The cycle time obtained is 0.1267 years. We have $M<T+N$, so corresponding profit per unit time for the retailer is $\$ 8559.39$ by purchasing 129.45 units. The concavity of the profit per unit time is exhibited in Figure 2.

Example 3. To demonstrate the scenario $M<N$, consider $M=0.6$ years and $N=0.8$ years. Then $\partial \pi_{3}(t) / \partial t=0$ gives cycle time $T=0.2260$ years. The profit is $\$ 7516.68$ and purchase quantity is 234.99 units. Figure 3 shows that profit obtained is concave.

Next, we study the variations in cycle time (Figure 4) and profit realization (Figure 5) by changing inventory parameters as $-40 \%,-20 \%, 20 \%$, and $40 \%$. The observations are as follows.

(1) (Figure 4) The retailer's cycle time is very sensitive to the credit period offered to the customer. Increase in $N$ 


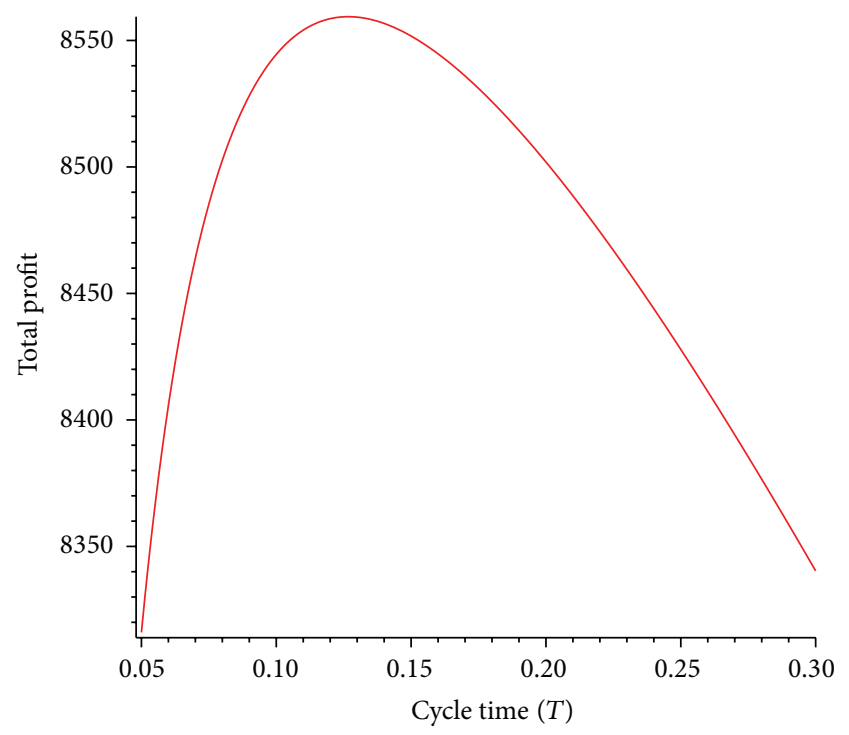

Figure 2: Concavity of total profit with respect to cycle time $T$ for $M<T+N$.

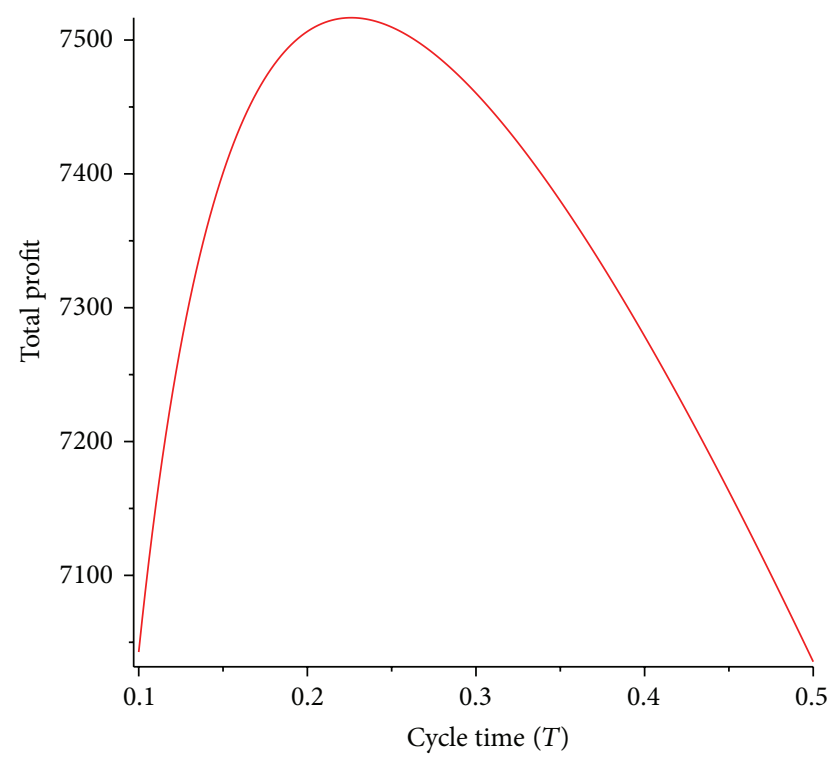

FIgURE 3: Concavity of total profit with respect to cycle time $T$ for $M<N$.

increases cycle time. The increase in ordering cost increases cycle time. Increase in demand and delay period $M$ forces retailer to order frequently. Increase in maximum life of deteriorating items increases cycle time. Cycle time is negatively sensitive to retail price. Other critical inventory parameters are interest charged and interest earned. Both decrease cycle time significantly.

(2) (Figure 5) The retailer's total profit per unit time increases sharply when demand and selling price of an item increase. Settling the account at a later date $M$ is also beneficial to the retailer. Though maximum lifetime of product is uncontrollable, it can be controlled to increase the profit. The retailer can adopt advance facility to extend

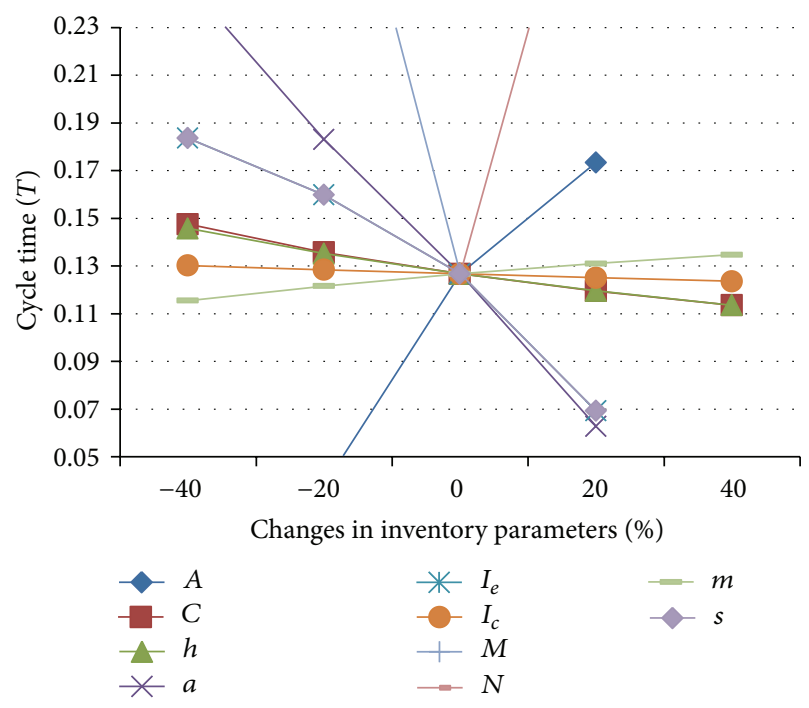

FIgURE 4: Sensitivity analysis for cycle time $(T)$.

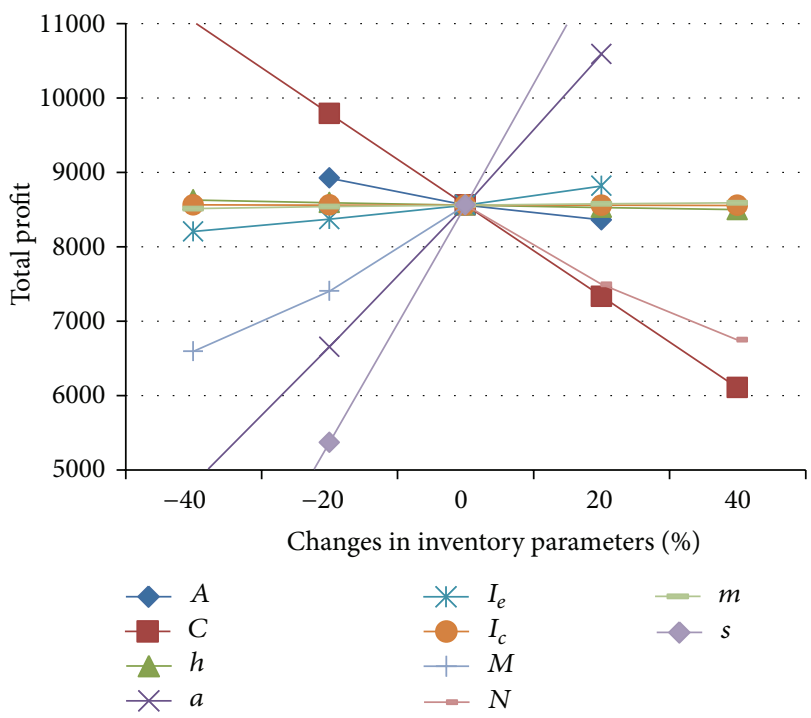

FIGURE 5: Sensitivity analysis for total profit.

life of the product. Increase in purchase cost decreases profit drastically.

The retailer must maintain the balance between the credit periods $M$ and $N$. By placing orders frequently the retailer will increase the ordering cost. So the trade-off is also required to combat between ordering cost and credit period M.

Figure 6 shows how smaller delay period encourages the decision maker to buy more quantity.

\section{Conclusions}

In this paper, ordering strategy is studied for the retailer when the product has fixed lifetime and is deteriorating in nature. It is established that the retailer should intelligently decide the payment time for the settlement of the accounts 


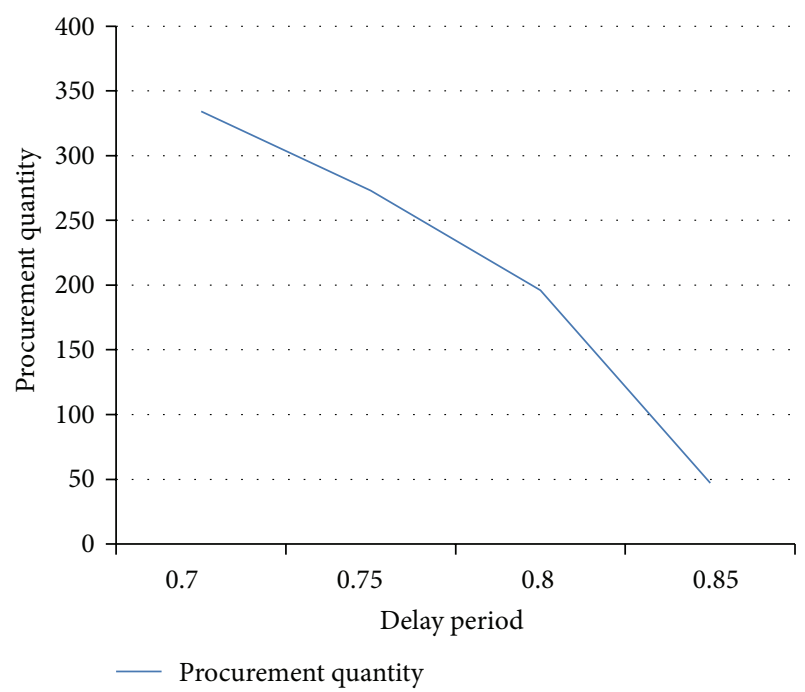

FIGURE 6: Procurement quantity versus delay period.

to the supplier and from the customer. This will reduce the risk of default from customers. The future study for stochastic demand or fuzzy demand will be more practical. Further research can be on the analysis of risk reduction using reliability theory.

\section{Conflict of Interests}

The authors declare that there is no conflict of interests regarding the publication of this paper.

\section{Acknowledgment}

The authors would like to thank all the reviewers for their constructive suggestions.

\section{References}

[1] S. K. Goyal, "Economic order quantity under conditions of permissible delay in payments," Journal of the Operational Research Society, vol. 36, no. 4, pp. 335-338, 1985.

[2] H. Soni, N. H. Shah, and C. K. Jaggi, "Inventory models and trade credit: a review," Control and Cybernetics, vol. 39, no. 3 , pp. 867-884, 2010.

[3] B. Sarkar, S. Saren, and H. M. Wee, "An inventory model with variable demand, component cost and selling price for deteriorating items," Economic Modelling, vol. 30, pp. 306-310, 2013.

[4] Y. F. Huang, "Optimal retailer's ordering policies in the EOQ model under trade credit financing," Journal of the Operational Research Society, vol. 54, no. 9, pp. 1011-1015, 2003.

[5] Y. F. Huang, "An inventory model under two levels of trade credit and limited storage space derived without derivatives," Applied Mathematical Modelling, vol. 30, no. 5, pp. 418-436, 2006.

[6] Y. F. Huang, "Optimal retailer's replenishment decisions in the EPQ model under two levels of trade credit policy," European
Journal of Operational Research, vol. 176, no. 3, pp. 1577-1591, 2007.

[7] J. T. Teng and C. T. Chang, “Optimal manufacturer's replenishment policies in the EPQ model under two levels of trade credit policy," European Journal of Operational Research, vol. 195, no. 2, pp. 358-363, 2009.

[8] B. Pal, S. S. Sana, and K. Chaudhuri, "Three stage trade credit policy in a three-layer supply chain-a production-inventory model," International Journal of Systems Science, pp. 1-25, 2013.

[9] P. M. Ghare and S. F. Schrader, "A model for exponentially decaying inventory," Journal of Industrial Engineering, vol. 14, no. 5, pp. 238-243, 1963.

[10] N. H. Shah and Y. K. Shah, "Literature survey on inventory models for deteriorating items," Economic Annals, vol. 44, pp. 221-237, 2000.

[11] S. K. Goyal and B. C. Giri, "Recent trends in modeling of deteriorating inventory," European Journal of Operational Research, vol. 134, no. 1, pp. 1-16, 2001.

[12] M. Bakker, J. Riezebos, and R. H. Teunter, "Review of inventory systems with deterioration since 2001," European Journal of Operational Research, vol. 221, no. 2, pp. 275-284, 2012.

[13] P. Leśniewski and A. Bartoszewicz, "LQ optimal sliding mode control of periodic review perishable inventories with transportation losses," Mathematical Problems in Engineering, vol. 2013, Article ID 325274, 9 pages, 2013.

[14] S. S. Sana, "Optimal selling price and lotsize with time varying deterioration and partial backlogging," Applied Mathematics and Computation, vol. 217, no. 1, pp. 185-194, 2010.

[15] B. Sarkar, "An EOQ model with delay in payments and stock dependent demand in the presence of imperfect production," Applied Mathematics and Computation, vol. 218, no. 17, pp. 8295-8308, 2012.

[16] B. Sarkar, "A production-inventory model with probabilistic deterioration in two-echelon supply chain management," Applied Mathematical Modelling, vol. 37, no. 5, pp. 3138-3151, 2012.

[17] B. Sarkar and S. Sarkar, "An improved inventory model with partial backlogging, time varying deterioration and stockdependent demand," Economic Modelling, vol. 30, pp. 924-932, 2013.

[18] M. Sarkar and B. Sarkar, "An economic manufacturing quantity model with probabilistic deterioration in a production system," Economic Modelling, vol. 31, pp. 245-252, 2013.

[19] B. Sarkar, S. S. Sana, and K. Chaudhuri, "An inventory model with finite replenishment rate, trade credit policy and pricediscount offer," Journal of Industrial Engineering, vol. 2013, Article ID 672504, 18 pages, 2013.

[20] B. Sarkar, "An EOQ model with delay in payments and time varying deterioration rate," Mathematical and Computer Modelling, vol. 55, no. 3-4, pp. 367-377, 2012.

[21] S. C. Chen and J. T. Teng, "Retailer's optimal ordering policy for deteriorating items with maximum lifetime under supplier's trade credit financing," Tech. Rep., William Paterson University, 2012.

[22] W. C. Wang, J. T. Teng, and K. R. Lou, “Seller's optimal credit period and cycle time in a supply chain for deteriorating items with maximum lifetime," European Journal of Operational Research, vol. 232, no. 2, pp. 315-321, 2013.

[23] J. T. Teng and S. K. Goyal, "Optimal ordering policies for a retailer in a supply chain with up-stream and down-stream trade credits," Journal of the Operational Research Society, vol. 58, no. 9, pp. 1252-1255, 2007. 


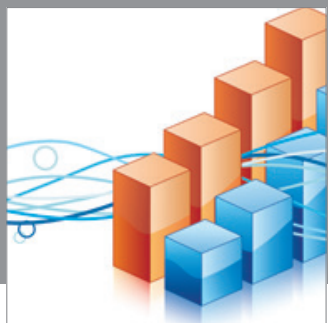

Advances in

Operations Research

mansans

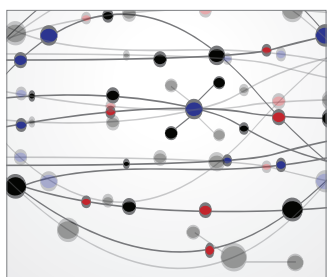

The Scientific World Journal
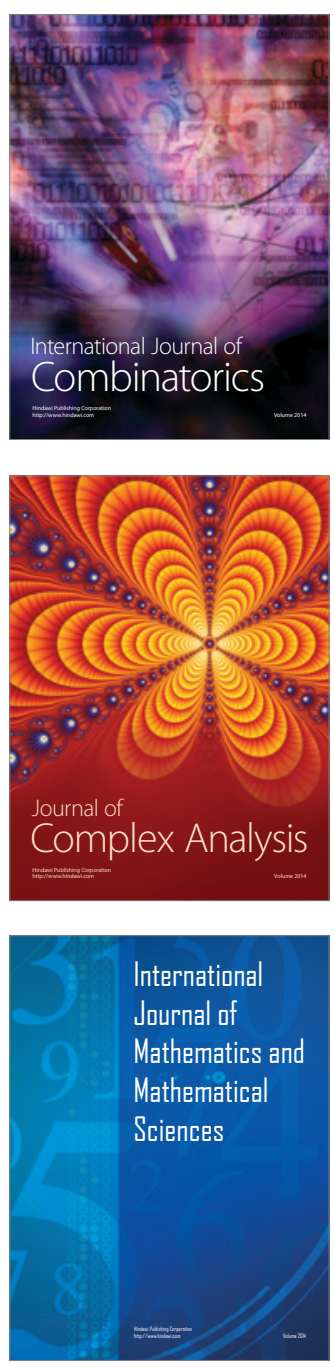
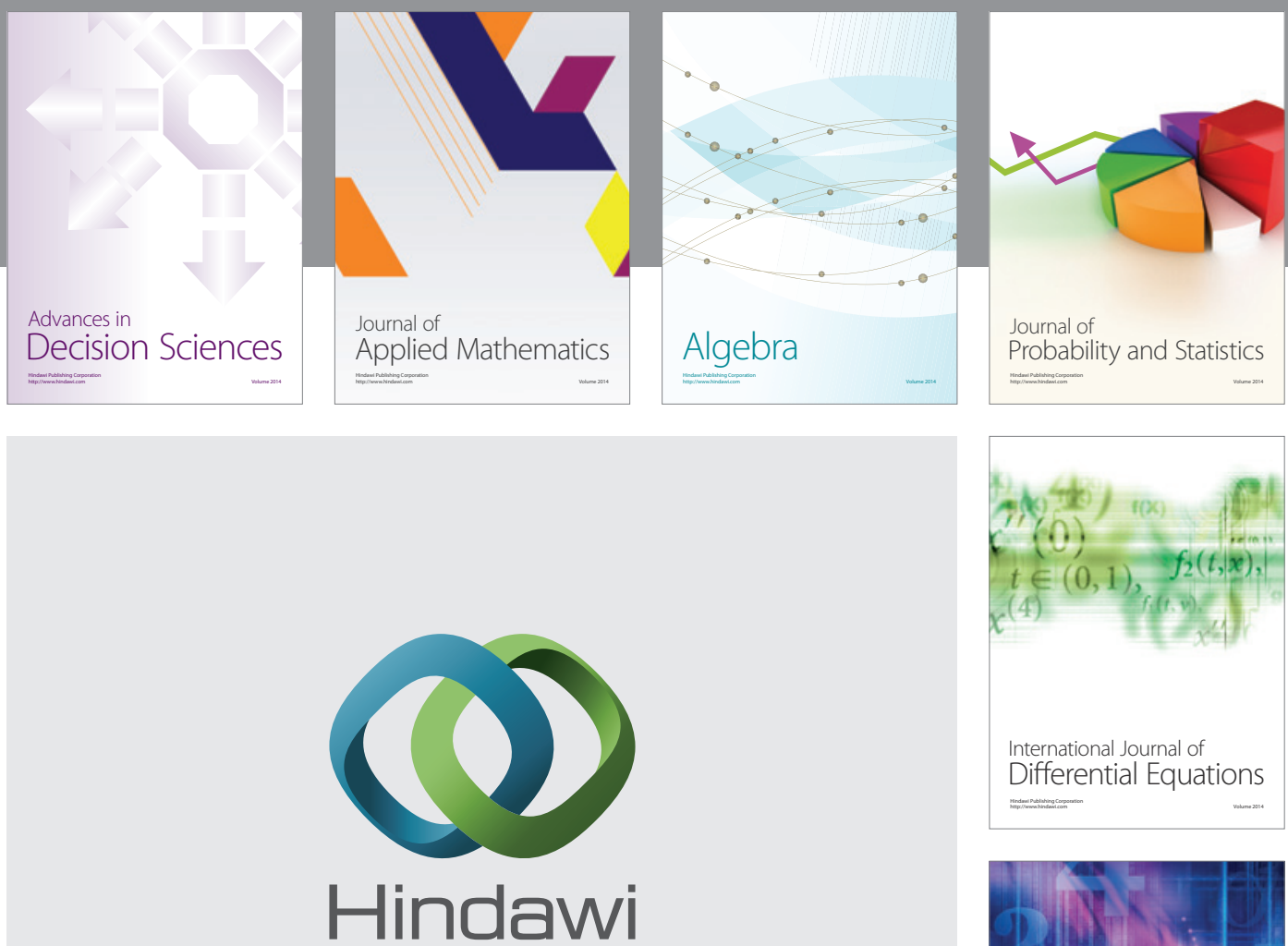

Submit your manuscripts at http://www.hindawi.com
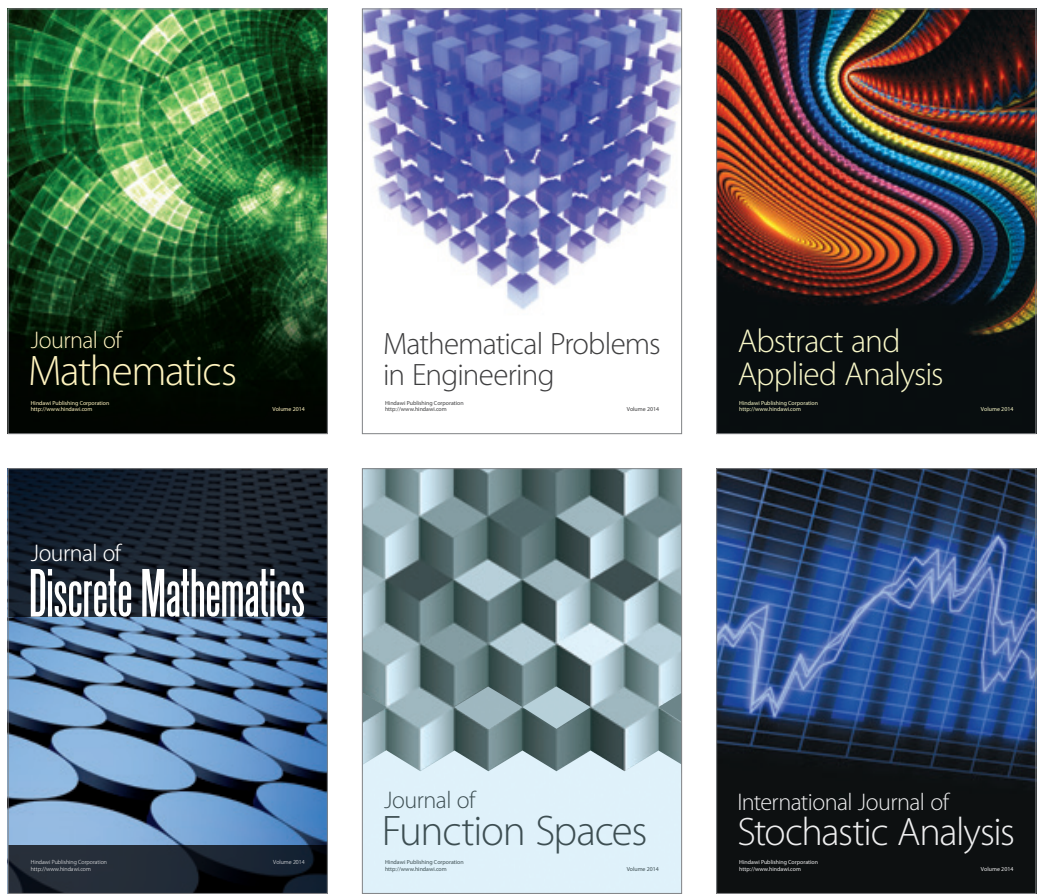

Journal of

Function Spaces

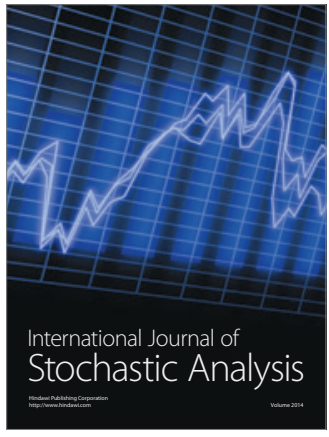

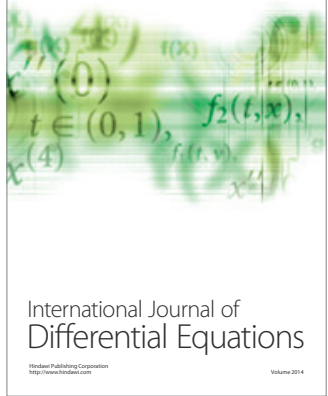
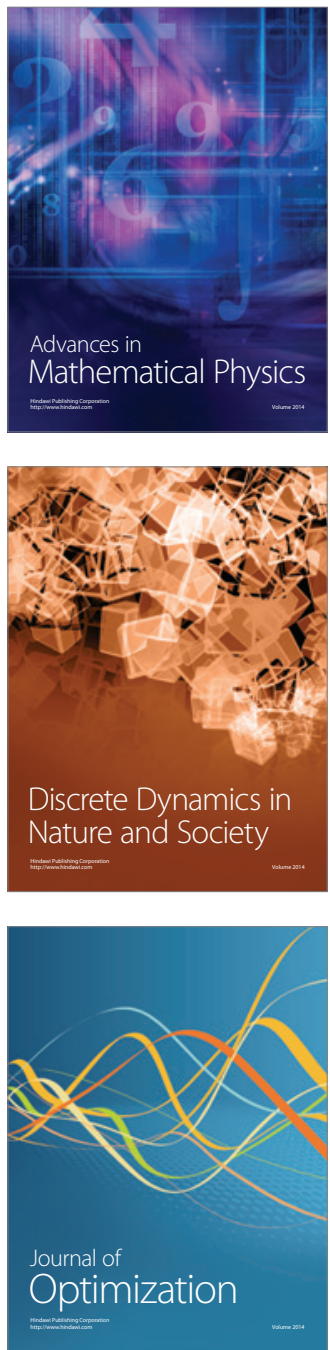